\title{
O Festival Garimpando Sabores e a ressignificação dos saberes e fazeres culinários de Mendanha
}

\section{"Garimpando Sabores" Festival and the resignification of Mendanha's culinary knowledge and practices}

\author{
Luciana Teixeira Silva ${ }^{1}$ \\ Nadja Maria Comes Murta ${ }^{2}$ \\ Silvia Regina Paes ${ }^{3}$
}

A pesquisa "O Festival Garimpando Sabores e a ressiginificação dos saberes e fazeres culinários de Mendanha" buscou desenvolver uma análise sistemática acerca da realização do Festival Garimpando Sabores, um evento focado na culinária que surgiu com o propósito de incluir os distritos rurais do município de Diamantina, Minas Gerais, na atividade turística, além de resgatar pratos, receitas, ingredientes e formas de preparos antigas. Estes, muitas vezes já esquecidos, podem, ao serem retomados, se transformar em atrativos, gerando também autoestima e sentimento de pertencimento àquelas comunidades.

A análise enfoca o caso específico da comunidade rural de Mendanha, verificando se o evento de fato estimulou a ressignificação dos saberes e fazeres culinários desta população. Através de uma abordagem que mescla o pensamento complexo e a abordagem qualitativa da pesquisa-ação, estruturada em questionários aplicados em três tipos distintos de público - cozinheiros que participaram do evento, moradores desta comunidade rural e membros da comissão organizadora do festival -, este método apreende as percepções dos atores sobre o evento e sua contribuição para a ressignificação desses conhecimentos tradicionais, que vinham se extinguindo em função de seu caráter de transmissão essencialmente oral, do êxodo rural e da situação de marginalidade econômico-social que alguns territórios, como as comunidades rurais no Vale do Jequitinhonha, tinham sido compelidos.

As discussões em torno dos resultados da pesquisa asseveram que a valorização da comida como atrativo turístico é mais complexa do que se imagina, indo além da possibilidade de geração de renda, da preservação da identidade local e da memória gustativa, perpassando o debate da introdução de inovações, autoestima das comunidades e perspectivas de médio e longo prazo. Apesar da verificação de retomada de saberes e fazeres tradicionais, há outros aspectos importantes a serem tratados, sobretudo comportamentais, culturais e de ordem econômica, que podem se tornar dificultadores para que se garanta uma maior efetividade e perenidade na ressignificação destes conhecimentos, sendo este um dos principais pontos em que o estudo pode contribuir para as reflexões acerca da construção da alimentação enquanto alimento simbólico, na medida em que esta, mais que um fenômeno fisiológico, é humano, permeado de subjetividades e individualidades. 
Palavras-chave: comunidades rurais; conhecimentos tradicionais; cultura alimentar; festival gastronômico; saberes e fazeres culinários.

Keywords: rural communities; traditional knowledge; food culture; gastronomic festival; culinary knowledge and practices.

1 Mestre em Estudos Rurais pela Universidade Federal dos Vales do Jequitinhonha e Mucuri.

2 Doutora em Ciências Sociais: Antropologia pela Pontifícia Universidade Católica de São Paulo.

3 Bacharel em Ciências Sociais, Doutora em Sociologia, Professora nos cursos da área da saúde na Faculdade de

Ciências Básicas e da Saúde e dos Mestrados em Saúde, Sociedade e Ambiente e em Estudos Rurais da UFVJM. 